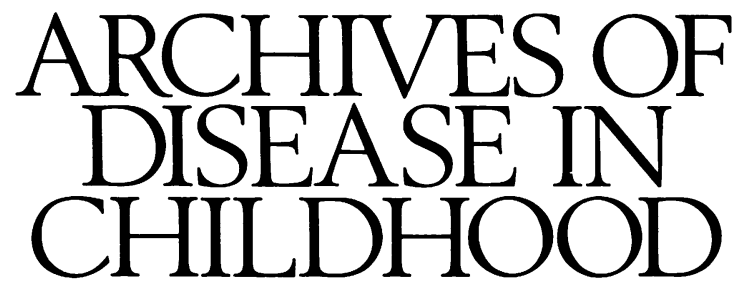

The fournal of the British Paediatric Association

\title{
Annotations
}

\section{Respiratory rate and pneumonia in infancy}

The World Health Organisation (WHO) programme to control acute respiratory infections uses simple clinical signs to identify pneumonia, to assess its severity and whether there is a need for hospitalisation, and to decide on the type of antibiotic treatment. The clinical signs must be appropriate for community health workers, nurses, and physicians in both outpatient and hospital settings. The clinical signs include cyanosis, inability to feed, subcostal retractions, wheezing, and respiratory rate thresholds. The respiratory rate (breaths per minute) thresholds are set at $\mathbf{6 0}$ for infants less than 2 months of age, 50 for infants from 2 to 12 months, and 40 for children aged 1 to 5 years. WHO recommends a repeat respiratory rate count for infants under 2 months of age when the initial count is 60 or higher.

Acute respiratory infection during early infancy presents a special challenge with respect to both assessment and management. Young infants have less specific clinical syndromes so that the clinical presentation of pneumonia is often similar to that of sepsis, meningitis, or a urinary tract infection. Non-specific signs such as inability to feed, fever, hypothermia, difficulty awakening, and convulsions were added in special WHO guidelines for the infant under 2 months. This new approach reflects the finding that acute respiratory infection has the highest incidence and mortality in young infants. Twenty to $30 \%$ of the total acute respiratory infection related childhood (under 5 years of age) mortality occurs in infants under 2 months of age. ${ }^{1}$

The usefulness of respiratory rate thresholds to identify pneumonia is a critical aspect of the programme. Several factors other than age and presence of a lower respiratory infection will affect the respiratory rate and its variability. These involve the method of counting (observation, auscultation, monitor), duration of counting interval, state of the child (awake, sleeping, feeding, and calm or agitated) and gender, as well as associated non-respiratory conditions such as fever, acidosis, dehydration, and malnutrition. There may also be differences between infant baseline respiratory rates and variability in infants living in developing and developed countries related to differences in low birth weight, nutrition, activity levels, genetic and other factors.

The recent article by Morley et al entitled 'Respiratory rate and severity of illness in babies under 6 months of age' sought to define the normal range of respiratory rate and assess the usefulness of a threshold respiratory rate of 50 to identify lower respiratory infection. ${ }^{2}$ In reviewing other published studies that describe the normal range of infant respiratory rates, a major methodological difference becomes apparent. Other published studies determined the mean respiratory rate in a relatively small number of infants over a prolonged period of time with continuous electronic monitoring while Morley et al determined the mean respiratory rate of a large number of infants during a very short period of time: three 15 second intervals. The study of Morley et al found overall a mean (SD) respiratory rate for awake infants seen in the hospital or home of 61 (18) and 61 (14) and 42 (12) for sleeping infants. Mean respiratory rates for each month of life were similar: $57,57,61,63,59$, and 59 respectively.

Determination of normal range of respiratory rate by electronic monitoring

Studies using continuous electronic monitoring for prolonged time periods are reviewed in table $1 .^{3-6}$ Mean respiratory rates (SD) are shown by the state of the infant (awake, active sleep, quiet sleep, and all states) and age. Studies using this method report a lower range of baseline mean respiratory rates for both awake and asleep infants. In contrast to Morley et al, each study also documented a decrease in mean respiratory rate with age. Hoppenbrouwers et al have also reported a lower mean respiratory rate of 4.7 to 5.9 in infant girls compared with boys. Although the numbers in the cited studies using electronic monitoring are small, their findings are supported by work published by Valman $e t$ al, who used a mean respiratory rate $\geqslant 60$ persisting for longer than one hour determined by electronic monitoring as a screen in newborns for sepsis or pneumonia. ${ }^{8}$ Only $29(1 \%)$ of 2789 infants screened had a respiratory rate $\geqslant 60$.

Determination of normal range of respiratory rate by observation

An ongoing (unpublished) community based study with twice weekly home visits in Lima, Peru, counted the respiratory rate by observation for 60 seconds in all infants aged less than 3 months and 3 months or older with a history of cough (C Lanata, personal communication). Table 2 shows the results of counts obtained in infants less than 12 months according to the infant's state. The age interval is up to but not including the next month. The mean counts are similar to data obtained by continuous monitoring. Differences between the data obtained by Lanata in Peru and by Morley 
Table 1 Mean respiratory rate according to the infant state in studies using continuous electronic monitoring (time interval)

\begin{tabular}{|c|c|c|c|c|c|c|c|c|}
\hline \multirow[t]{2}{*}{ State of infant } & \multicolumn{2}{|c|}{$\begin{array}{l}\text { Hoppenbrouwers et al } \\
\text { (12 hours) }\end{array}$} & \multicolumn{2}{|c|}{$\begin{array}{l}\text { Curzi-Dascalova et at } \\
\text { (one sleep cycle) }\end{array}$} & \multicolumn{2}{|c|}{$\begin{array}{l}\text { Ashton et al } \\
\text { (3 hours) }\end{array}$} & \multicolumn{2}{|c|}{$\begin{array}{l}\text { Richards et al } \\
(22 \text { hours })\end{array}$} \\
\hline & $\begin{array}{l}\text { No of } \\
\text { subjects }\end{array}$ & $\begin{array}{l}\text { Mean }(S D) \\
\text { respiratory rate }\end{array}$ & $\begin{array}{l}\text { No of } \\
\text { subjects }\end{array}$ & $\begin{array}{l}\text { Mean }(S D) \\
\text { respiratory rate }\end{array}$ & $\begin{array}{l}\text { No of } \\
\text { subjects }\end{array}$ & $\begin{array}{l}\text { Mean }(S D) \\
\text { respiratory rate }\end{array}$ & $\begin{array}{l}\text { No of } \\
\text { subjects }\end{array}$ & $\begin{array}{l}\text { Mean }(S D) \\
\text { respiratory rate }\end{array}$ \\
\hline $\begin{array}{l}\text { Awake: } \\
1 \text { week } \\
1 \text { month } \\
2 \text { months } \\
3 \text { months } \\
4 \text { months } \\
5 \text { months } \\
6 \text { months }\end{array}$ & $\begin{array}{l}8 \\
8 \\
8 \\
8 \\
8 \\
\\
8\end{array}$ & $\begin{array}{l}50(10) \\
48(6) \\
48(7) \\
41(8) \\
40(9) \\
\text { NA } \\
43(10)\end{array}$ & & & & & & \\
\hline $\begin{array}{c}\text { Active sleep: } \\
1 \text { week } \\
1 \text { month } \\
2 \text { months } \\
3 \text { months } \\
4 \text { months } \\
5 \text { months } \\
6 \text { months }\end{array}$ & $\begin{array}{l}8 \\
8 \\
8 \\
8 \\
8 \\
\\
8\end{array}$ & $\begin{array}{l}51(8) \\
42(6) \\
36(6) \\
31(3) \\
30(3) \\
\mathrm{NA} \\
28(4)\end{array}$ & $\left\{\begin{array}{l}22 \\
11 \\
14 \\
10\end{array}\right.$ & $\begin{array}{l}48(9) \\
64(14) \\
57(16) \\
43(10)\end{array}$ & 22 & $47(9)$ to 54 (11) & & \\
\hline $\begin{array}{l}\text { Quiet sleep: } \\
1 \text { week } \\
1 \text { month } \\
2 \text { months } \\
3 \text { months } \\
4 \text { months } \\
5 \text { months } \\
6 \text { months }\end{array}$ & $\begin{array}{l}8 \\
8 \\
8 \\
8 \\
8 \\
\\
8\end{array}$ & $\begin{array}{l}38(9) \\
34(4) \\
30(5) \\
25(3) \\
26(3) \\
\text { NA } \\
24(4)\end{array}$ & $\left\{\begin{array}{l}22 \\
11 \\
14 \\
10\end{array}\right.$ & $\begin{array}{l}36(7) \\
50(11) \\
46(11) \\
38(10)\end{array}$ & 22 & $43(13)$ to $45(10)$ & & \\
\hline $\begin{array}{l}\text { Awake and slee } \\
1 \text { week } \\
1 \text { month } \\
2 \text { months } \\
3 \text { months } \\
4 \text { months } \\
5 \text { months } \\
6 \text { months }\end{array}$ & & & & & & & $\begin{array}{r}36 \\
41 \\
50 \\
97 \\
91\end{array}$ & $\begin{array}{l}43(16) \\
39(6) \\
37(6) \\
31(6) \\
27(4)\end{array}$ \\
\hline
\end{tabular}

NA, not available.

Table 2 Mean respiratory rate (per minute) observed at first measurement by age in all infants under 6 months of age and in infants 6-11 months of age with reported cough in Canto Grande, Lima, Peru (Fanuary-Fune 1989)

\begin{tabular}{|c|c|c|c|c|c|c|c|}
\hline \multirow[t]{2}{*}{ State of infant } & \multicolumn{7}{|c|}{ Age (months) } \\
\hline & 0 & 1 & 2 & 3 & 4 & 5 & $6-11$ \\
\hline $\begin{array}{l}\text { Sleeping: } \\
\text { No of examinations } \\
\text { Mean rate } \\
\text { SD }\end{array}$ & $\begin{array}{r}542 \\
46 \cdot 18 \\
9 \cdot 14\end{array}$ & $\begin{array}{r}868 \\
43 \cdot 12 \\
7 \cdot 21\end{array}$ & $\begin{array}{r}852 \\
41 \cdot 34 \\
7 \cdot 47\end{array}$ & $\begin{array}{r}169 \\
38.88 \\
7.07\end{array}$ & $\begin{array}{r}126 \\
36.56 \\
7.87\end{array}$ & $\begin{array}{l}109 \\
36 \cdot 85 \\
8 \cdot 28\end{array}$ & $\begin{array}{r}359 \\
34 \cdot 38 \\
7 \cdot 09\end{array}$ \\
\hline $\begin{array}{l}\text { Breastfeeding: } \\
\text { No of examinations } \\
\text { Mean rate } \\
\text { SD }\end{array}$ & $\begin{array}{r}253 \\
50 \cdot 36 \\
7.77\end{array}$ & $\begin{array}{r}671 \\
48.98 \\
7.04\end{array}$ & $\begin{array}{r}696 \\
47 \cdot 55 \\
7 \cdot 13\end{array}$ & $\begin{array}{r}141 \\
45.07 \\
6.78\end{array}$ & $\begin{array}{r}115 \\
44.69 \\
7.09\end{array}$ & $\begin{array}{r}91 \\
42.84 \\
6.52\end{array}$ & $\begin{array}{r}328 \\
40.82 \\
5.83\end{array}$ \\
\hline $\begin{array}{l}\text { Awake and calm: } \\
\text { No of examinations } \\
\text { Mean rate } \\
\text { SD }\end{array}$ & $\begin{array}{r}264 \\
49 \cdot 56 \\
9.51\end{array}$ & $\begin{array}{r}897 \\
48.33 \\
6.96\end{array}$ & $\begin{array}{r}1373 \\
47 \cdot 82 \\
6.62\end{array}$ & $\begin{array}{r}467 \\
44 \cdot 74 \\
7 \cdot 07\end{array}$ & $\begin{array}{r}491 \\
43.76 \\
6.09\end{array}$ & $\begin{array}{r}410 \\
43.65 \\
6.36\end{array}$ & $\begin{array}{r}2249 \\
40.89 \\
5.34\end{array}$ \\
\hline $\begin{array}{l}\text { Awake and not calm but not crying: } \\
\text { No of cases } \\
\text { Mean rate } \\
\text { SD }\end{array}$ & $\begin{array}{r}17 \\
46 \cdot 79 \\
9 \cdot 24\end{array}$ & $\begin{array}{l}46 \\
50 \cdot 67 \\
11 \cdot 41\end{array}$ & $\begin{array}{r}74 \\
48 \cdot 11 \\
8 \cdot 89\end{array}$ & $\begin{array}{l}44 \\
44 \cdot 67 \\
10 \cdot 09\end{array}$ & $\begin{array}{l}32 \\
44 \cdot 21 \\
5 \cdot 71\end{array}$ & $\begin{array}{l}24 \\
44.56 \\
6.94\end{array}$ & $\begin{array}{r}220 \\
41 \cdot 26 \\
6 \cdot 32\end{array}$ \\
\hline
\end{tabular}

et al in Australia/Great Britain may reflect their respective populations and/or the different methods used to count respirations. The respiratory rate in the Peru study was counted by observing abdominal and chest wall movements for 60 seconds with an electronic timer, but in Australia/ Great Britain counts were made with a stethoscope or hand on the abdomen for 15 seconds. The electronic timer allows the field worker to count the rate without needing to watch a timer during the same period. Work in Denver, Colorado, suggests that counting respirations with a stethoscope is similar to counting with an electronic monitor and results in slightly higher mean counts than when observing (EAF Simoes et al, personal communication). Simultaneously obtained observed and monitored counts in 101 infants and children found mean monitored counts to be 2-3 breaths/ minute higher than mean observed counts. The monitor and stethoscope appear to pick up small breaths that are not appreciated when observing for chest/abdominal movement. After reviewing the paper of Morley et al, we compared three 15 second counts obtained by auscultation with counts obtained by observation by two investigators at the same time in 10 infants. The counts obtained by auscultation were an average of 14 breaths per minute higher than those obtained by observing abdominal and chest wall movement. It is also possible that touching an infant with a stethoscope or hand may cause an increased level of agitation that increases the respiratory rate. Counting for 15 seconds rather than 60 seconds may also result in a slightly raised respiratory rate. In Denver, 30 second counts obtained immediately before and after a 60 second count were analysed for infants less than 2 months. Doubling of a 30 second count obtained by observation or monitoring results in a higher mean count of $2-4$ breaths per minute compared with the 60 second count. Counting for a 15 
second period may further increase this difference. The method of counting may account for the high mean rates and variability reported by Morley et al.

\section{Usefulness of respiratory rate thresholds to predict pneumonia}

The second aim of the study of Morley $e t$ al was to assess the usefulness of respiratory rate thresholds to identify children with severe illness or pneumonia. Studies assessing the usefulness of respiratory rate thresholds should clearly. define the criteria for acute lower respiratory infection, preferably using radiography findings, the method of counting respirations, and determine sensitivity, specificity, and predictive values for varying threshold levels. Unfortunately the classification of lower respiratory infection in the Morley et al paper was unclear, especially in relation to the diagnostic category of non-specific acute lower respiratory infection. There were only six clearly documented cases of pneumonia. The mean (SD) respiratory rate of 30 infants with findings on radiography was 65 (21) compared with 60 (16) in other infants. No association was found between a threshold greater than 50 and lower respiratory infection. The issue of the usefulness of a raised respiratory rate as an indicator of severe non-respiratory illness in infants less than 2 months of age is unclear and requires further research.

The value of the current WHO criteria for identifying acute lower respiratory infection in early infancy was reassessed from data collected in Denver, Colorado and Vellore, India. While these studies have been published, 910 this analysis of early infancy is unpublished. In Denver, 70 infants under 2 months of age and 20 infants between 2 and 3 months who presented to the hospital outpatient clinic with cough or congestion were prospectively enrolled in an aetiological study. 9 A clinical diagnosis of a lower respiratory infection based on radiography findings ( 42 cases) or in cases without radiography based on rales (crepitations) or wheezing (seven cases) was made in 49 infants (70\%) less than 2 months of age. The presence of retractions or a respiratory rate $\geqslant 60$ (WHO criteria) had a sensitivity of 42 / $49(85 \cdot 7 \%)$, specificity of $11 / 21(52 \cdot 4 \%)$, positive predictive value $42 / 52(80.8 \%)$, negative predictive value $11 / 18$ $(61 \cdot 1 \%)$, and $\chi^{2} p<0 \cdot 01$. A respiratory rate $\geqslant 60$ alone had a sensitivity of $31 / 49(63 \cdot 2 \%)$, specificity of $12 / 21(57 \cdot 1 \%)$, positive predictive value $31 / 40(77 \cdot 5 \%)$, negative predictive value $12 / 30(40 \%)$, and was not significant by $\chi^{2}$. A respiratory rate $\geqslant 60$ was significantly associated with lower respiratory infection $(p<0.05)$ when all 90 infants less than 3 months were analysed. The sensitivity was $39 / 63$ (62\%), specificity $17 / 27(63 \%)$, positive predictive value $39 / 49$ (79.6\%), and negative predictive value $17 / 41(41 \cdot 5 \%)$. If a threshold of 70 is used, the sensitivity decreases to $9 / 63$ (14\%). If a threshold of 50 is used, the specificity decreases to $15 / 27(56 \%)$.

Unpublished data from the study carried out in Vellore, India (EAF Simoes et al, personal communication) assessed the usefulness of clinical signs in 76 infants under 2 months of age presenting with runny nose or cough to the clinic or hospital. A lower respiratory infection was identified in $59 / 76(78 \%)$ infants based on crepitations, wheeze, bronchial breath sounds, or radiological findings. A respiratory rate $\geqslant 60$ had a sensitivity of $34 / 59(58 \%)$, specificity of $15 / 17(88 \%)$, positive predictive value $34 / 36(94 \%)$, negative predictive value $15 / 40(38 \%)$, and $\chi^{2} \mathrm{p}<0.01$.

The specificity of the respiratory rate $\geqslant 60$ may be improved without appreciably decreasing sensitivity by obtaining a repeat respiratory rate in infants without other signs of lower respiratory infection such as wheezing, retractions, or inability to feed. Data from Denver on persistence of raised respiratory rate in children with upper respiratory infection indicates that a repeat count 45 to 60 minutes later will be less than the threshold in more than two thirds of the patients with an upper respiratory infection in contrast to patients with lower respiratory infection who will usually maintain a raised respiratory rate (EAF Simoes $e t$ al, personal communication). This observation is supported by field trials in Lima, Peru of respiratory rates counted in neonates during twice a week home visits. Approximately half of the counts above 60 were below 60 when retaken several minutes later. ${ }^{11}$

Although respiratory rate is a useful predictor of lower respiratory infection in young infants, it does not correlate well with hypoxia. ${ }^{9}$ The presence of subcostal retractions is a more useful predictor of hypoxia. The Denver study found retractions as a predictor for hypoxia had a sensitivity of $75 \%$, specificity of $71 \%$, predictive value of $75 \%$, and $\chi^{2}$ $\mathrm{p}<0.05 .^{9}$ A discriminant function analysis has been reported by Prapphal et al from Thailand for infants less than 2 months (N Prapphal, S Limudomporn, S Chomdej et $a l$, paper presented at INCLEN, Mexico 1990). Using nasal flaring, chest retraction, refusal to eat, decreased body weight, duration of cough, and abdominal distension, the function could predict hypoxia with a sensitivity of $76 \%$, specificity $85 \%$, and positive predictive value of $84 \%$.

A research project in Swaziland assessed the current WHO guidelines to identify lower respiratory infection in infants 2 months to 5 years. ${ }^{12}$ The WHO criteria predicted chest radiography documented pneumonia with a sensitivity of $72 \%(18 / 25)$, specificity of $85 \%$ (285/337), positive predictive value $26 \%(18 / 70)$, and negative predictive value $85 \%$ (285/337).

\section{Conclusion}

More data is needed in developing countries to assess the usefulness of the WHO guidelines relating to infants less than 2 months. Relatively little is known about aetiology and clinical presentation of pneumonia and other severe illness for this age group despite the very high mortality rates experienced by these infants. This area is identified as the single most important research priority by the WHO acute respiratory infection programme. Effective case management, together with measles and pertussis vaccination, are the major strategies available to reduce the world's excessive childhood mortality related to acute respiratory infection. The paper by Morley et al helps to clarify the importance of the method used in measuring the respiratory rate and the need for further research to assess the value of clinical signs in predicting pneumonia and hypoxia. However the conclusion that respiratory rate is not a valid indicator in infants is premature and not supported by a review of the existing literature.

STEPHEN BERMAN ERIC A F SIMOES

Department of Pediatrics,

University of Colorado Health Sciences Center, 4200 East Ninth Avenue,

Denver, Colorado 80262, USA

Instituto de Investigacion Nutrictional,

CLAUDIO LANATA

Lima, Peru

1 Spika JS, Munshi MH, Woityniak B, et al. Acute lower respiratory infections: major cause of death in children in Bangladesh. Ann Trop Paediat 1989;9:33-9.

2 Morley CJ, Thornton AJ, Fowler MA, et al. Respiratory rate and severity of illness in babies under 6 months old. Arch Dis Child 1990;65:834-7.

3 Hoppenbrouwers T, Harper RM, Hodgman JE, et al. Polygraphic studies of normal infants during the first six months of life. II. Respiratory rate and variability as a function of state. Pediatr Res $1978 ; 12: 120-5$. 
4 Curzi-Dascalova L, Gaudebout C, Dreyfus-Brisac C. Respiratory frequencies of sleeping infants during the first months of life: correlation between values in different sleep states. Early Hum Dev 1981;5:39-54.

5 Ashton $R$, Connolly $K$. The relation of respiration rate and heart rate to sleep states in the human newborn. Dev Med Child Neurol 1971;13:180-7.

6 Richards JM, Alexander JR, Shinebourne EA, et al. Sequential 22-hour profiles of breathing patterns and heart rate in 110 full-term infants during their first 6 months of life. Pediatrics 1984;74:763-77.

7 Hoppenbrouwers T, Hodgman JH, Steinman MB, et al. Gender differences in respiratory rates and apnea density in infants between birth and six months of age. Pediatr Res 1979;13:359.

8 Valman HB, Wright BM, Lawrence C. Measurement of respiratory rate in the newborn. $B M \mathcal{F}$ 1983;286:1783-4.
9 Berman S, Shanks MB, Feiten D, et al. Acute respiratory infections during the first three months of life: Clinical, radiologic and physiologic predictors of etiology. Pediatr Emerg Care 1990;6:179-82.

10 Cherian T, John TJ, Simoes EAF, Steinhoff MC, John M. Evaluation of simple clinical signs for the diagnosis of acute lower respiratory tract infection. Lancet 1988;ii: $125-8$.

11 World Health Organisation. Fourth programme report, 1988-1989, ARI programme for control of acute respiratory infections. Geneva: WHO, 1990;7:32. 12 World Health Organisation. Fourth programme report, 1988-1989, ARI prog-
ramme for control of acute respiratory infections. Geneva: WHO, 1990;7:31. 